\title{
Advancing Early STEM Identity Development: Insights into Early Childhood Mathematics Education
}

\author{
Alyse C. Hachey \\ University of Texas at El Paso, TX, United States
}

There is now focused attention on the deliberate introduction of science, technology, engineering and mathematics (STEM) discipline instruction earlier in children's schooling, with the immediate goal of fostering foundational content and skills and nurturing early STEM identity development in pre-primary children. Early STEM identity development is conceived as a social identity bound by early and deliberate exploration of STEM and an explicit recognition of the relevance of STEM-related activity in daily life (Hachey, 2020; Hachey, An \& Golding, 2021). It is expressed in young children engaging in authentic STEM-related practices and roles, and it is grounded in the socio-educational interactions that contextualize meaningful early acquisition of STEM content knowledge. Yet many children, particularly those from low socioeconomic status backgrounds and ethnically/racially minoritized children) do not conceive of themselves in STEM roles nor do they develop STEM academic identities by the end of elementary school (Hachey, 2020; Talafian et al., 2019). While both state and federal early public schooling in the U.S. has traditionally been focused on cultivating young children's literacy development, several recent Early Childhood Education policy reports appeal for more/equal emphasis of STEM discipline instruction in the early years (i.e., STEM Smart, 2013; Early STEM Working Group, 2017). This calls for research that digs deeper both into aspects of children's early STEM thinking and how Early Childhood Education teachers can nurture its development.

In particular, early mathematical reasoning has emerged as a significant area of interest in the development of young children's early STEM (and overall) academic identity. The learning of mathematics and the development of mathematical identity specifically is now linked as function of young children engaging with and doing mathematics in everyday life, as well as the subjective appraisal of related subjective cognitive-emotional experience (Black et al., 2019; Grootenboer \& Edwards-Groves, 2019). Further, the mathematical thinking ability by kindergarten is now being highlighted as a key component of both early school readiness and later academic success across all subject areas (i.e., Claessens \& Engel, 2013; Watts et al., 2014). This stems from a plethora of research that positions infants, toddlers, preschoolers and early elementary children as capable of 
engaging with diverse mathematical skills and understandings (Hachey, 2013a).

However, despite advances in research and theory, in terms of mathematical pedagogy, there remain gaps in the knowledge about how best to systematically help young children to learn mathematical concepts. To address this gap, the first article by Baroody et al. in this special issue on Early Childhood Mathematics Education seeks to make explicit the connection between promoted teaching practices and mathematical learning outcomes with young children. It draws from the rich theorizing of Sarama \& Clements (2009) on hypothetical learning trajectories [HLTs] for young children (i.e., theoretically and empirically supported sequences of developmental levels and activities for promoting progress to each level) to critically and empirically examine HLTs as an instructional tool for working with preschoolers on patterning. Findings from Baroody et al. point to the potential of early mathematics instruction based on HLTs, as well as specific aspects of effectively engaging 3 and 4-year-olds with patterns.

Moving beyond specific classroom intervention, the second article in this special issue by Lucero looks at the role of communities of practice during an after-school gardening project. The use of school gardens as a learning space has been increasing across the U.S.; the goal of school-based gardens is not only to develop future gardeners by learning gardening skills, but to also utilize gardens as a context and hands-on tool for academic subject learning (Cramer \& Ball, 2019). Lucero's article emphasizes real-life contextualized mathematics engagement during gardening as a means of fostering early mathematics learning, and more generally, STEM identity development in kindergarteners- $2^{\text {nd }}$ graders. Her findings support other research that finds that informal and extension learning settings can provide substantial, high-quality STEM-focused social learning opportunities for young children (Hurst et al., 2019).

The first two articles in this special issue, while applying different lenses and methodology, offer new insight into pedagogically engaging young children in early mathematics. Both Baroody et al. and Lucero's articles add to a growing body of research that contends that teacher mediated explorations of hands-on materials have greater benefits for young children's early learning than free play or direct instruction (Cutter-Mackenzie \& Edwards, 2013; Fisher et al., 2013; Pyle, DeLuca \& Danniels, 2017; Weisberg, Hirsh-Pasek \& Golinkoff, 2013). Specifically, young children learn foundational math (and science) concepts, as well as gain early STEM identity development, through hands-on inquiry with manipulatives and experimentation, in combination with teacher mediated sense-making of these experiences. The Early Childhood teacher's role, then, becomes to support meaningful connections to prior implicit knowledge, extend hands-on experiences, provide related academic language and to introduce and facilitate practice of specific disciplinary concepts. Such teaching is interactional and 
improvisational (Forzani, 2014), as the Funds of Knowledge (Moll, 2019) that young children bring from home, along with the socio-educational encounters they engage in at school, serve as resources for teaching and learning (Brooker, 2010; Cutter-Mackenzie \& Edwards, 2013; Erikson Institute, 2017; Pyle, DeLuca \& Danniels, 2017; McCormick Smith \& Chao, 2018).

Moreover, the complexity of the interactional and improvisational nature of early mathematics teaching and learning is magnified when we consider the teacher-- and teacher-in-training-her/himself. Pre-service and in-service teacher identity and beliefs are shaped by their upbringing, culture and life experience-including memories of their past teachers and mathematical experiences (Aldemir \& Sezer, 2009; Hachey, 2009; Hachey, $2013 \mathrm{~b}$ ). The last three articles in this special issue contribute to the wider literature averring that preconceived beliefs about content and about teaching filter knowledge acquisition and influence experiences during teacher education (i.e., Çelikten, 2006), thus serving to inform teachers' philosophy of teaching. Yet, they extend this specifically to include the Early Childhood Education teacher.

The need to reframe the negative mathematical beliefs of Early Childhood teachers is a common thread in much of the Early Childhood Mathematics Education literature (i.e., Geist, 2015; Hachey, 2009; 2013a/b). Owens (2007-08) argues that teachers (at all levels) need to become selfregulated, confident learners with a sense of ownership in order to further develop their own identity as mathematical thinkers, and to in turn, promoting this in others. Hence, it is during teacher preparation that attitudes towards Early Childhood Mathematics Education can be (even must be) addressed. Yet, how to impactfully and effectively do this during teacher preparation is still in question. This idea is explored empirically by Gilken, Longley \& Guirguis in the third article in this special issue. Their results suggest that constructivist curricular interventions in Early Childhood teacher preparation courses may serve to counteract negative attitudes towards mathematic and to positively impact pre-service teacher mathematical abilities and future mathematical algebraic practice with infants and toddlers.

Garvis et al. (2012) note that pre-service Early Childhood Education teachers are only beginning to form the "wisdom of practice" and as such, not only their attitudes towards mathematics but their beliefs on knowledge acquisition impacts their own later teaching practice. Status differentiation and differences in past power issues can lead some pre-student teachers to assume knowledge is handed down to them and some to assume knowledge comes from empirical evidence, reason and activities that they themselves are capable of pursuing (Schommer-Aikins, 2004). This directly influences how they in turn go on to mathematically engage young children, as is explicated in the fourth article in this special issue by Davis. Davis's article critically links pre-service teacher mathematical identity to young children mathematical identity development. Her findings shine a light on role of Early 
Childhood teachers in contributing to mathematics socialization and the cycle of socially reproduced inequity in mathematics outcomes for students of color.

The final article in this special issue by Reyes and Rothstein-Fisch suggests that addressing and reframing negative mathematics attitudes likely needs to go beyond pre-service intervention and into in-service professional development. Some past research with practicing Early Childhood Education teachers has suggested that just like in pre-service preparation, professional development experiences, too, are likely filtered by teacher beliefs and confidence in their mathematical content knowledge (Chen et al, 2014). Reyes and Rothstein-Fisch's article helps to confirm past findings and provides insight into the un-packing that may be necessary during professional development focused on Early Childhood Mathematics Education.

Young children's socio-educational interaction with teachers and peers offers rich opportunities to learn foundational mathematical concepts and practice basic skills, as well as for children to begin to identify themselves as competent STEM thinkers and doers. Yet, the data show that less than $10 \%$ of Kindergarten through $2^{\text {nd }}$ grade instructional time in the U.S. is devoted to STEM discipline content (Pantoya, Aguirre-Munoz \& Hunt, 2015). This special issue of JME, and all the articles therein, are a step in widening the conversation and deepening the knowledge to recognize and include young children and their teachers in discourses on teaching, learning and identity development both in mathematics education, and in STEM education more widely.

\section{References}

Aldemir, J. \& Sezer, O. (2009). Early childhood education pre-service teachers' images of teacher and beliefs about teaching. Inonu University Journal of the Faculty of Education, 10(3),105-122.

Black, L., Choudry, S., Pickard-Smith, K. \& Williams, J. (2019). Theorising the place of emotion-cognition in research on mathematical identities: The case of early years mathematics. ZDM Mathematics Education, 51, 379-389. https://doi.org/10.1007/s11858-018-01021-9

Brooker, L. (2010). Learning to play, or playing to learn? Children's participation in the cultures of homes and settings?. In Engaging play, Edited by: Brooker, L. \& Edwards, S. Open University Press. (pp. 3953).

Çelikten, M. (2006). Culture and teacher metaphors used in educational system. Erciyes University Journal of the Institute of Social Science, 2, 269-283.

Chen, J.Q., McCray, J., Adams, M. Leow, C. (2014). A survey study of early childhood teachers' beliefs and confidence about teaching early math. Journal of Early Childhood Education, 42, 367-377. https://doi.org/10.1007/s10643-013-0619-0 
Claessens, A., \& Engel, M. (2013). How important is where you start? Early mathematics knowledge and later school success. Teachers College Record, 115(6), 1-29.

Cramer, S.E. \& Ball, A.L. (2019). Wild Leaves on Narrow STEMs: Exploring Formal and Non-formal Education Tensions Through Garden-Based Learning. Journal of Agricultural Education, 60(4), 35-52 https://doi.org/10.5032/jae.2019.04035

Cutter-Mackenzie, A \& Edwards, S. (2013). Toward a Model for Early Childhood Environmental Education: Foregrounding, Developing, and Connecting Knowledge Through Play-Based Learning. Journal of Environmental Education, 00958964, 44(3), 195-213. https://doi.org/10.1080/00958964.2012.751892

Early Childhood STEM Working Group (2017), Early STEM Matters, Providing high-quality STEM experiences for all young learners: A policy report by the Early Childhood STEM Working Group. Erikson Institute. Available from: http://d31wefg3pyezlb.cloudfront.net/docs/Early_STEM_Matters_FIN AL.pdf

Erikson Institute (2017). Early STEM matters: A policy report by the early childhood STEM working Group. http://ecstem.uchicago.edu/

Fisher K.R., Hirsh-Pasek K., Newcombe N., Golinkoff R.M. (2013). Taking shape: Supporting preschoolers' acquisition of geometric knowledge through guided play. Child Development, 84(6), 1872-1878.

Forzani, F. M. (2014). Understanding "Core Practices" and "Practice-Based" Teacher Education: Learning From the Past. Journal of Teacher Education, 65(4), 357-368. https://doi.org/10.1177/0022487114533800

Garvis, S., Fluckiger, B. \& Twigg, D. (2012). Exploring the beliefs of commencing early childhood education graduate students: Providing insights to improve teacher education programs. Australian Journal of Teacher Education, 37(1), 93-105. http://ro.ecu.edu.au/ajte/vol37/iss1/6

Geist, E. (2015). Math anxiety and the "math gap": How attitudes towards mathematics disadvantages students as early as preschoo1. Education, 135(3), 328-336. https://eis.hu.edu.jo/deanshipfiles/pub110226807.pdf\#page $=64$

Grootenboer, P \& Edwards-Groves, C. (2019). Learning mathematics as being stirred into mathematical practices: an alternative perspective on identity formation. International Journal on Mathematics Education, 51(2), 433-444. https://doi.org/10.1007/s11858-018-01017-5

Hurst, M.A.; Polinsky, N., Haden, C.A., Levine, S.C. \& Uttal, D.H. (2019). Leveraging research on informal learning to inform policy on prompting early STEM. Society for Research in Child Development, $32(3), 1-13$. 
Hachey, A.C. (2009). I hate math: What we want young children NOT to learn. Texas Child Care Quarterly, Fall 2009, 2-7. https://www.childcarequarterly.com/fall09_story1.html

Hachey, A. C. (2013). The early childhood mathematics education revolution. Early Education \& Development, 24(4), 419-430. https://doi.org/10.1080/10409289.2012.756223

Hachey, A.C. (2013b). Teachers' beliefs count: A study of teacher beliefs and practices in early childhood mathematics education (ECME). NHSA Dialog: A Research-to-Practice Journal for the Early Childhood Field, $\quad$ 16(3), 77-85. https://journals.charlotte.edu/dialog/article/view/109

Hachey, A.C. (2020). Success for all: Fostering early childhood STEM identity. Journal of Research in Innovative Teaching and Learning, 13(1), 135-139.

https://www.emerald.com/insight/content/doi/10.1108/JRIT-01-2020$\underline{0001 / \text { full/html }}$

Hachey, A.C., An, S.A. \& Golding, D.E. (2021). Nurturing kindergartener's early STEM academic identity though Makerspace Pedagogy. Early Childhood Education Journal.

https://link.springer.com/content/pdf/10.1007/s10643-021-01154-9.pdf

McCormick Smith, M. \& Chao, T. (2018). Critical science and mathematics early childhood education: Theorizing Reggio, play, critical pedagogy into an actionable cycle. Education Sciences, 8, 1-16.

Moll, L.C. (2019). Elaborating Funds of Knowledge: Community-oriented practices in international Contexts. Literacy Research: Theory, Method, \& Practice 68(1). https://journals.sagepub.com/doi/full/10.1177/2381336919870805

Owens, K. (2007-08). Identity as a mathematical Thinker. Mathematics Teacher Education and Development, 9, 36-50.

Pantoya, M.E., Aguirre-Munoz, Z. and Hunt, E.M. (2015), Developing an engineering identity in Early Childhood, Journal of Engineering Education, 6(2), 61-68. https://doi.org/10.19030/ajee.v6i2.9502

Pyle, A., DeLuca, C. \& Danniels, E. (2017). A scoping review of play-based pedagogies in kindergarten education. Review of Education, 5(3), 311351. https://doi.org/10.1002/rev3.3097

Sarama, J., \& Clements, D. H. (2009). Early childhood mathematics education research: Learning trajectories for young children. Routledge.

Schommer-Aikins, M. (2004). Explaining the epistemological belief system: Introducing the embedded systemic model and coordinated research approach. Education psychologist 39(1) 19-29.

https://doi.org/10.1207/s15326985ep3901_3 
STEM Smart: Lessons Learned From Successful Schools (2013, December). Nurturing stem skills in young learners, prek-3. STEM smart briefearly childhood learning, Washington, DC.

http://docplayer.net/7429009-Stem-smart-brief-stem-smart-lessonslearned-from-successful-schools.html

Talafian, H., Moy, M.K., Woodard, M.A. and Foster, A.N. (2019), STEM identity exploration through an immersive learning environment, Journal for STEM Education Research, 2, 105-127. https:/doi.org/10.1007/s41979-109-00018-7

Watts, T.W., Duncan, G.J, Siegler, R.S. \& Davis-Kean, P.E. (2014). What's past is prologue: Relations between early mathematics knowledge and high school achievement. Educational Researcher, 43(7), 352-360. https://doi.org/10.3102/0013189X14553660

Weisberg D.S., Hirsh-Pasek K., Golinkoff R.M. (2013). Guided play: Where curricular goals meet a playful pedagogy. Mind, Brain, and Education, 7, 104-112. https://doi.org/10.1111/mbe.12015

\section{Guest Editor for this Special Issue:}

Alyse C. Hachey, Ph.D., is an Associate Professor at The University of Texas at El Paso (UTEP). She serves as the Teacher Education Department CoChair, Division Director of BELSS [Bilingual Education, Early Childhood Education, Literacy \& Sociocultural Studies], Lead Early Childhood Faculty and Co-director of the College of Education Makerspace within the College of Education. Her teaching and research interests focus on early childhood cognition and curriculum development, particularly related to EC STEM education. 